\title{
Entre a academia de boxe e o boxe da academia: um estudo etnográfico
}

\author{
Flávio Py Mariante Neto* \\ Mauro Myskiw** \\ Marco Paulo Stigger ${ }^{* * *}$
}

\begin{abstract}
Resumo: Este trabalho traz elementos para a discussão sobre a diversidade dos significados das práticas "esportivas" por pessoas comuns, no cotidiano das cidades. Faz isso a partir de um estudo etnográfico da prática de boxe no contexto de uma academia de fitness da cidade de Porto Alegre, em vista de como esta articula os sentidos do boxe dos boxeadores e do fitness dos alunos, e se isto implica numa lógica de desesportivização. Após a análise e a interpretação do material empírico produzido, pudemos concluir que a prática estudada tem um aspecto híbrido, no sentido de que se caracteriza pela inserção (muito dinâmica, tensa, disputada) de elementos e significados da "academia de boxe" e do "boxe da academia". Nesse sentido, não seria estranho referirmos a simultaneidade da "desesportivização do boxe" e "esportivização do fitness". Palavras-chave: Boxe; Academia; Etnografia; Diversidade
\end{abstract}

\section{INTRODUÇÃO}

A oferta e a prática "de boxe" em academias "de fitness 1 " podem ser facilmente observadas em muitas cidades brasileiras, constituindo espaços simbólicos onde o ensino/treinamento, a aprendizagem e a execução dos mais diversos tipos socos, esquivas/proteções e deslocamentos produzem sentidos que sustentam a afiliação de

\footnotetext{
"Mestre em Ciências do Movimento Humano pela UFRGS. E-mail: flaviomariante@hotmail.com "Professor da Universidade Estadual do Oeste do Paraná (Paraná- Brasil). E-mail: mmyskiw@hotmail.com

"."Professor Associado ao Departamento de Educação Física. Universidade Federal do Rio Grande do Sul (Rio Grande do Sul - Brasil). E-mail: stigger@adufrgs.ufrgs.br

${ }^{1} A$ discussão realizada por Malysse (2002) nos ajudou a definir essa expressão.
} 
pessoas com distintos interesses (lazer, aptidão física, sociabilidade, saúde, entre outros). E é com o intuito de colaborar na compreensão desses espaços, principalmente dessa prática, que realizamos este estudo etnográfico no contexto de uma sala de boxe no interior de uma academia que oferta outras "modalidades", como a musculação, a ginástica e o jiu-jítsu.

Tal pesquisa foi desenvolvida na esteira de um debate já presente no trabalho de Stigger (1997), sobre a diversidade da prática de futebol por grupos de veteranos, de Damo (2003), sobre a diversidade configuracional do futebol e de Marques, Almeida e Gutierrez (2007), sobre a heterogeneidade do esporte contemporâneo. Mas, diferente destes trabalhos, este estudo do boxe - uma "modalidade individual" - no âmbito de uma academia de fitness coloca na pauta da discussão a diversidade/heterogeneidade dentro de um grupo. Nesse sentido, também tratamos de forma crítica a forma como os esportes hegemônicos (oficiais, midiáticos, profissionais) ocupam lugar de destaque nos debates acadêmicos, em detrimento das práticas cotidianas, realizadas por pessoas comuns ${ }^{2}$, estas implicadas por uma diversidade de significados (STIGGER, 2002). Ainda, nos foi importante a discussão empreendida por Padiglione (1995) a cerca da crescente dificuldade em definir o esporte com base em critérios rígidos (competição, jogo e regras, por exemplo), diante de sua heterogeneidade, sobretudo de suas variações internas que criam um novo cenário, rico em alteridades, terreno fértil para a investigação etnográfica.

Em que pese alguns elementos de uma representação hegemônica da prática do boxe, não é difícil encontrarmos referências culturais, estas fortemente baseadas no esporte oficial, de que se trata de uma luta, num ringue cercado de espectadores, entre dois oponentes bastante treinados, que executam técnicas corporais, sob os olhares atentos de treinadores, árbitros/juízes, apostadores,

${ }^{2}$ No contexto deste trabalho, entendemos por pessoas comuns aquelas que praticam esporte de modo não profissional, como divertimento, lazer, atividade física ou outros interesses, no cotidiano. 
empresários, jornalistas, políticos, familiares, telespectadores, etc. O cinema, em especial, nos apresentou estes elementos ao produzir personagens e histórias de boxeadores em filmes (entre eles, "Rocky, o lutador" e Maggie, a "Menina de Ouro"), ou ao retratar a vida de boxeadores em documentários ${ }^{3}$, como também o fizeram as emissoras de TV, ao promoverem e transmitirem as lutas de boxe, como a do norte-americano Mike Tyson e do brasileiro Acelino Freitas, conhecido como Popó, por exemplo) ${ }^{4}$. Estas referências foram eficientes na oferta de sentidos à prática do boxe, baseadas em atributos como a coragem e a resistência corporal frente aos punhos do adversário, a virilidade masculina, a violência física, a atmosfera viciada negociações escusas, a luta pela ascensão social, o enfrentamento à pobreza, à discriminação racial ou de gênero.

Um trabalho emblemático, que trouxe avanços para a compreensão dessas representações, sobretudo como elas se corporificam no dia-a-dia dos treinamentos e como se relacionam com o contexto social, foi realizado por Löic Wacquant, a partir de um estudo etnográfico de uma academia de boxe (o gym), numa comunidade afro-americana de baixa renda na cidade de Chicago, resultando em diversas publicações (WACQUANT, 1998; 2001; $2002 ; 2003 ; 2007)^{5}$. É a partir deste trabalho e em relação a ele que passamos a problematizar a sala de boxe no interior da academia de fitness, ou melhor, o boxe da academia. Um rápido olhar comparativo nos permitiu formular um quadro que apontou diferenças significativas entre a academia de boxe (o gym descrito por Wacquant) e o boxe da academia que investigamos.

\footnotetext{
${ }^{3} \mathrm{O}$ maior de todos (2001) e Muhammad Ali (2001) são exemplos de documentários realizados sobre a vida de boxeadores.

${ }^{4}$ Ao nos referirmos ao cinema, o nosso objetivo é ressaltar atributos bastante marcantes na representação coletiva do boxe, para, em seguida, tratar da sua diversidade/pluralidade na academia.

${ }^{5}$ Löic Wacquant realizou um trabalho etnográfico de três anos em um ginásio de boxe, treinando, realizando entrevistas e participando de lutas como atleta e como segundo, o indivíduo que acompanha o lutador durante o combate.
} 
Quadro 1 - Relação preliminar entre o boxe apresentado nos textos de Wacquant (1998; 2002) e o encontrado em academias

\begin{tabular}{|c|c|}
\hline BOXE EM WACQUANT & BOXE EM ACADEMIAS \\
\hline $\begin{array}{l}\text { Esporte relacionado à ascensão social e status } \\
\text { social ("saída profissional"). }\end{array}$ & $\begin{array}{l}\text { Esporte como lazer, busca de "forma física", entre } \\
\text { outros interesses. }\end{array}$ \\
\hline $\begin{array}{l}\text { Boxe é a única prática no espaço do gym. Os } \\
\text { praticantes são os boxeadores ou aspirantes a tal. }\end{array}$ & $\begin{array}{l}\text { O boxe é praticado num espaço onde se praticam } \\
\text { também outras modalidades. Os praticantes são os } \\
\text { "alunos" da academia. }\end{array}$ \\
\hline Predominantemente masculino. & Pratic ado por homens e mulheres. \\
\hline $\begin{array}{l}\text { Corpo visto como uma arma, uma máquina e uma } \\
\text { ferramenta. } \\
\text { Cenário social de escassas oportunidades de } \\
\text { trabalho, onde a pobreza está refletida na vida de } \\
\text { todos os praticantes do gym. Grupo com } \\
\text { características homogêneas. }\end{array}$ & $\begin{array}{l}\text { O discursos dos "alu nos" sobre o corpo envolvem } \\
\text { saúde, estética, forma física, etc. } \\
\text { Cenário com diferentes classes sociais. Grupo com } \\
\text { características heterogêneas. }\end{array}$ \\
\hline
\end{tabular}

Este quadro não tem o propósito de reduzir o trabalho de Wacquant $(1998 ; 2002)$ às características apresentadas, tampouco dizer que o boxe em academias é exatamente como retratado esquematicamente acima. Tratou-se de um exercício de problematização que, juntamente com as constatações sobre as representações do boxe "do cinema" e "da TV", nos possibilitou estranhar a prática do boxe "da academia" onde o estudo foi realizado ${ }^{6}$. A partir dessa reflexão inicial, passamos a nos questionar sobre esse boxe que é praticado na academia de fitness: como se materializa, na academia, uma prática usualmente conhecida como boxe? Quais são as semelhanças e diferenças entre as representações e prática conhecida e reconhecida como boxe e aquilo que se pratica no cotidiano dos alunos da academia em pauta? Em que medida a prática na academia articula sentidos do boxe dos boxeadores e do fitness dos alunos? Estaríamos diante de uma lógica de desesportivização do boxe?

\section{Considerações MEtOdolóGICAS}

A busca de respostas para essas questões nos conduziu à perspectiva etnográfica de investigação, o que significa inserir este

\footnotetext{
${ }^{6}$ Não estamos restringindo o cenário (ou o mundo) do boxe a este dos cinemas, das telas de TV e dos trabalhos realizados por Wacquant. Ao contrário disso, nosso objetivo é ressaltar atributos bastante marcantes na representação coletiva desta prática, para, em seguida - no decorrer das descrições etnográficas do boxe na academia -, tratar da diversidade e da pluralidade.
} 
estudo num ponto de vista antropológico. Se tradicionalmente a Antropologia buscou compreender os costumes de povos distantes da realidade vivida pelo pesquisador, atualmente ela continua com o objetivo de "olhar a cultura do outro 'de dentro'" (OLIVEIRA, 1996, p. 25), mesmo que esse outro faça parte da sua própria sociedade.

No campo acadêmico dos estudos socioculturais sobre o esporte $^{7}$, a etnografia tem sido utilizada para compreender como práticas esportivas bastante corriqueiras fazem sentido para os seus praticantes e como elas se inserem no seu dia-a-dia. Trata-se de entendê-las como parte da sua cultura e de visualizá-las na sua relação com o seu "em torno" (STIGGER, 2007, p. 35), ou seja, a partir das relações que se estabelecem com as rotinas, as concepções e os modos de vida desses indivíduos.

A partir dessas reflexões, realizamos a investigação em uma academia que tem uma história de 18 anos no universo dos locais que oferecem o boxe como modalidade ${ }^{8}$, e é referência nesse tipo de prática em Porto Alegre. Nela são oferecidas aulas a pessoas de várias características e interesses no que se refere ao boxe, as quais o vêem a partir de diferentes perspectivas, como competição, defesa pessoal, atividade física, etc. Ademais, sendo o proprietário (e professor) da academia um ex-atleta de boxe que hoje ensina essa luta para pessoas que nem sempre estão interessadas em competir, isso constituiu um rico ponto de análise no tocante aos significados que ele confere ao boxe, e aqueles que são atribuídos pelos alunos. Sendo uma academia que oferecia o boxe como uma entre outras modalidades de fitness, também implicou na possibilidade de estar atento às características próprias daquele espaço, o que poderia proporcionar análises diferentes das encontradas em outros estudos.

\footnotetext{
${ }^{7}$ Quando nos referimos aos "estudos socioculturais sobre o esporte", estamos nos afastando da demarcação de uma área muitas vezes tratada como Sociologia do Esporte. No caso dessa investigação, apesar de nos apoiarmos num olhar Antropológico, utilizamos a primeira expressão no sentido de ampliar a abordagem que foi desenvolvida, a qual se sustenta em referenciais de diversas áreas como: a sociologia; a antropologia; a história; e a filosofia.

${ }^{8}$ Utilizamos a expressão "modalidade" com uma expressão retirada no campo. Usa-se esse termo para designar o tipo de atividade oferecida pela academia. Outros exemplos de modalidades seriam: musculação, ciclismo, ginástica, jiu-jítsu, entre outras.
} 
A partir dessas decisões, foram feitas observações ${ }^{9}$ quatro vezes por semana, especialmente no turno da noite. Nesses períodos, registraram-se dados oriundos das conversas informais, comportamentos, dinâmicas de funcionamento das aulas, diálogos entre alunos, entre professores e alunos e outras situações que ajudaram a buscar as questões que o trabalho suscitava.

Após o uso desse procedimento e da conseqüente seleção de pessoas que pudessem fornecer elementos úteis para resolver as questões de estudo (STIGGER, 2007), utilizamos entrevistas semiestruturadas, considerando que elas podem oferecer um acesso privilegiado às representações dos interlocutores sobre as suas práticas, via seus discursos (MAGNANI, 1997). A partir disso, os nossos colaboradores foram selecionados e aqueles que se dispuseram ${ }^{10}$ realizaram entrevistas pautadas por um roteiro preestabelecido, porém, com um caráter "aberto", na perspectiva de uma conversa (BURGESS, 1997).

\section{3 É TREINO DE BOXE OU AULA DE FITNESS?}

Em um primeiro olhar, talvez fosse fácil responder a essa questão. Afinal, se trata de uma academia de musculação e ginástica, local que os indivíduos procuram, em princípio, para cuidar do corpo, emagrecer, hipertrofiar músculos, diminuir dobras e aumentar perímetros - lugar de emoldurar o corpo e colocá-lo "no lugar". Um espaço de realimentações de padrões estéticos e morfológicos onde o intuito é, pois, moldar-se. Uma academia, também com um olhar apenas superficial, seria muito diferente dos tradicionais salões de treinamento de boxe que ainda estão no imaginário de muitas pessoas:

\footnotetext{
${ }^{9}$ Entre os meses de Outubro de 2009 e Abril de 2010, foram registradas cinqüenta observações, perfazendo um total de cento e cinqüenta páginas de diários de campo. O registro era feito a partir das funções atribuídas por Winkin (1998) e se caracterizava por uma descrição do que foi percebido durante a aula sendo, quando necessário, ligado (na forma de anotações) a trabalhos sobre o tema em questão. Além disso, no final do diário, colocavam-se as sensações do pesquisador e suas relações com o campo de pesquisa, perfazendo assim as três exigências teóricas do autor.
}

${ }^{10}$ Todos os entrevistados assinaram o Termo de Consentimento Livre e Esclarecido. 
materiais empoeirados, ringues que forjam indivíduos/lutadores que precisam do esporte para sair da grave situação social em que se encontram; local com armários antigos onde se guardam roupas esfarrapadas e mazelas de uma vida sofrida, e onde se vestem ataduras, calções de treino velhos e a esperança de uma vida melhor. Lugares diferentes, antagônicos, com poucas possibilidades de convívio, já que o primeiro é a materialização do culto ao corpo, e o segundo uma fábrica de boxeadores ${ }^{11}$.

Porém, nesse caso o papel do pesquisador é questionar o que esses olhares dizem sobre esses universos. Interessa desconfiar de questões que passam despercebidas ou prontamente são respondidas no senso comum. Assim, o nosso intuito foi o de compreender como o boxe praticado em academias de fitneess, local em que os ditames da estética e boa forma se sobrepõem às questões esportivas (SAUTCHUCK, 2007), se relaciona com os clássicos salões de treinamento. Para tanto, selecionamos freqüentadores e fragmentos de observações que nos possibilitaram esse entendimento e as posteriores discussões teóricas que esses dados suscitaram.

\section{BOXE DA ACADEMIA}

Como ponto de partida, selecionamos Diego, praticante de musculação e aluno esporádico de boxe, e Vítor, freqüentador assíduo dos treinamentos e que não realiza outras atividades físicas. Sobre eles e os seus objetivos com o uso do boxe, foram registrados dois diálogos:

\footnotetext{
${ }^{11}$ Essas duas perspectivas já foram referidas na introdução desse trabalho.
} 
Chego em cima da hora: $21 \mathrm{~h} 00 \mathrm{~min}$ e a aula anterior (Body Pump) está acabando e as últimas alunas estão saindo. Vou ao vestiário e encontro Vítor e Diego. Vítor está colocando as ataduras, e Diego tomando suplemento alimentar depois do seu treino de musc ulação. Segue entre eles o seguinte diálogo:

Fernando: Vai treinar boxe hoje?

Diego: Não, só vim fazer ferro (musculação).

Vítor: Tu vem no boxe só às vezes...

Diego: Pois é, só queria emagrecer, já consegui.

Vítor: Pode ser perigoso (rindo), se destreinar, quando aparecer, pode tomar um dire to no queixo.

Diego: Aí nem faço luva, não me preocupo com isso, quero só treinar no saco e pular corda pra emagrecer.

Vítor: Aí é barbada (num tom de brincadeira).

Diego: Vou ver se venho amanhã. Amanhã é dia de fazer aeróbico.

Vítor: Ta bem.

Enquanto a aula não começa, converso [pesquisador] com Diego, aluno de boxe e musculação, e que me diz que não vai treinar. Pergunto a ele o motivo já que está na academia no horário da aula, ele me responde: "Acho que não vou treinar boxe, só de vez em quando, vou ficar só puxando ferro hoje. Só queria perder 5\% de gordura e já consegui."

No primeiro diálogo percebe-se a diferença em relação aos seus objetivos: enquanto Vítor concentra sua fala na dificuldade em aprender as técnicas do boxe de defesa e ataque mediante a pouca assiduidade nas aulas, Diego discorre sobre seus objetivos estéticos colocando as questões técnicas em um lugar secundário, focando seu discurso nos resultados obtidos pelo treinamento de boxe. Ao dizer "vou ver se venho amanhã, é dia de fazer aeróbico", coloca o esporte não como uma luta, mas como uma possibilidade de obter os resultados que um exercício cardiovascular proporciona. Isso fica materializado, também, no segundo diálogo em que o aluno diz que já conseguiu o que queria com o boxe: "perder cinco por cento de gordura" e, por isso, não vê outro motivo para continuar treinando. No caso de Diego, muitas vezes foi visto praticando musculação no mesmo horário da aula de boxe; esse aluno não é regular nas aulas e evidencia, com suas atitudes, pouca preocupação em aprender a lutar boxe, a preocupação predominante do aluno é "secar"12. Essa afirmação é exemplificada na seguinte passagem durante uma atividade ministrada por Ricardo:

\footnotetext{
${ }^{12}$ Essa expressão significa diminuir o percentual de gordura para que seus músculos fiquem mais aparentes.
}

Movimento, Porto Alegre, v. 18, n. 01, p. 103-123, jan/mar de 2012. 
A aula de hoje teve quatro pessoas [...]. Trabalho com Eduardo no saco de pancada grande e Diego e Vítor no saco pequeno. Ricardo diz para fazermos três séries de um minuto e meio em cada um dos equipamentos. Fizemos o que o professor pediu e, após isso, ele dá um intervalo para que tomemos água. Na volta, Ricardo pede para colocarmos luvas grandes e capacetes para fazermos sparring. Eduardo, Vítor e eu colocamos os acessórios. Segue entre Diego e Ricardo e seguinte diálogo:

Diego: Não to a fim de fazer luva, queria dar uma "secada", posso ficar batendo no saco só?

Ricardo: Tu quem sabe, bate no saco então que eles lutam.

Diego: Ok.

Ao ouvir o diálogo entre os dois, Eduardo diz, em tom de brincadeira: "Quer secar, vai correr na esteira". Todos riem e Diego fica batendo no saco até o fim da aula enquanto nós três fizemos exercícios de sparring.

Entre as mulheres, também foi identificado uma diversidade no que diz respeito aos objetivos dos alunos com a prática. Em razão da aula de boxe ser, frequientemente, realizada em duplas, a interação entre os participantes é dependente, muitas vezes, do empenho do seu colega. Quanto a isso, Renata, quando perguntada sobre qual a parte da aula prefere, fala os motivos de não gostar de treinar com Laura, aluna esporádica de boxe e frequientadora de outras atividades da academia como a musculação e o jump, responde:

$\mathrm{Eu}$ gosto mais quando a gente faz luva porque é mais emocionante. $\mathrm{O}$ único problema é que, por exemplo, [...] a Laura, ela não se esforça - é ruim treinar com ela. O Ricardo manda baixar ela não abaixa - eu acho ruim isso. [...] O Ricardo fala uma coisa ou tu fala uma coisa e ela não faz. [...]. Ela não faz aquilo que o professor fala.

E, quando perguntada sobre quais motivos que, em sua opinião, levam Laura a continuar treinando, Renata conclui: "ela não gosta, ela já me disse que não gosta, ela tá ali só pra emagrecer, então, se tá ali pra isso, nunca vai se concentrar na técnica mesmo". Como pode ser percebido, parece que se estabelece um conflito em relação aos significados atribuídos àquela aula, entre Renata (que vê no boxe uma possibilidade de lutar) e Laura, que encontra, no boxe, uma forma de emagrecer. Assim como Diego, Laura é vista com pouca 
frequiência nas aulas de boxe, porém, muitas vezes foi vista realizando outras atividades na academia. Essa diversidade entre as duas frequientadoras foi relatada na seguinte passagem:

A aula de hoje foi dada por Ricardo [...]. Na primeira parte da aula, Ricardo fez um aquecimento em que todos os participantes se revezaram no speed bag, teto-solo, corda de esquiva, corda de pular e vermelho. [...] Na segunda parte da aula, Ricardo pediu para que formássemos duplas e realizássemos exercícios de defesa e ataque. Faço dupla com Vítor e, ao nosso lado, estão Renata e Laura. Ricardo pede para começarmos e Laura visivelmente não se empenha em realizar o que Ricardo propõe. No caso de Renata, ao contrário, se concentra em realizar as tarefas com afinco. Porém, Laura continua praticar sem dedicar-se aos esforços relativos à aprendizagem das técnicas. Renata fica visivelmente irritada por não conseguir treinar como queria (para luta). Ao final da aula, quando Laura havia ido embora, Renata se aproxima de mim e diz: "Tu viu né? Que saco treinar com essa guria, ela não se esforça nem um pouco. Se ela só quer emagrecer, vai fazer outra coisa ao invés de lutar boxe."

Esse excerto nos leva a perceber o quanto o boxe, apesar de ser considerado um esporte individual, se vincula a uma "aprendizagem coletiva" (WACQUANT, 2002, p. 138), que depende da interação entre os alunos. Nesse aspecto, identificamos divergências entre praticantes que, por atribuírem significados diferentes às aulas de boxe, consideram que os seus colegas não se comportam como o esperado, quando se trata de praticar uma luta, especialmente no que se refere à aprendizagem das suas técnicas.

Isso se evidenciou nos depoimentos dos alunos e nos excertos dos diários apresentados, a partir dos quais pode ser percebido - do ponto de vista dos professores e de parte dos alunos - que mesmo uma aula de boxe da academia deveria estar pautada mais pelo desenvolvimento de aptidões de luta e menos pelo que, na maior parte das vezes, se espera de uma aula de fitness. Assim, na perspectiva do professor e de vários alunos, os demais praticantes deveriam estar naquele local para lutar boxe, sustentados por uma lógica pelo menos próxima daquela identificada nos salões de treinamento, como os que foram estudados por Wacquant (2001) e Faria (2005). E, dessa forma, os praticantes que não se comportassem minimamente de acordo com os objetivos e significados vividos 
naqueles contextos, seriam mal vistos pelos alunos que freqüentam as aulas com maior assiduidade e com interesses relacionados à academia de boxe (gym).

Entretanto, diferente dessas pesquisas, na academia por nós estudada, não identificamos alunos que tivessem o objetivo de competir ou de lutar o boxe profissionalmente. Assim, conferir a esse espaço características do boxe de rendimento ${ }^{13}$ seria referir apenas parcialmente os objetivos dos alunos e os significados por eles atribuídos ao boxe. Por outro lado, imputar a esse local somente as características do fitness, seria, mais uma vez, negar o interesse pelo que o caracteriza como luta, aspecto presente nos dados apresentados até aqui. Então, ainda não havendo uma resposta para essa questão, pretendemos, a partir de agora, voltar o olhar para alguns pontos em que essas práticas se relacionam nas falas de seus alunos e professores.

Começamos por Ricardo, professor da academia. Essa escolha se deu por ser ele uma referência importante acerca da análise dessas relações, já que esse colaborador foi um praticante de boxe profissional nos EUA que, ao chegar ao Brasil, abriu uma academia de musculação e ginástica, em cujo espaço, posteriormente inseriu as aulas de boxe nesse espaço. E ele discorre sobre essa mudança:

Num ginásio, nos Estados Unidos, as pessoas não dão muita bola pra ti, só se tu mostrar talento, se não tu fica seis meses pulando corda e batendo no saco e ninguém te enxergar, lá eles querem é que tu lute, não tem essa de atividade física. Tu tens que ter teu material, tua luva, até teu speed bag e ninguém vai segurar manopla pra ti, a não ser que tu pague cinco ou dez dólares, e quando tu sobe num ringue é pra tomar porrada mesmo porque lá o objetivo é lutar, então tem que ter talento pra isso [...]. Quando eu cheguei aqui no Brasil foi diferente, se eu fizesse

\footnotetext{
${ }^{13}$ Utilizamos "boxe de rendimento" pautados pela noção de "Esporte de Rendimento", utilizada corriqueiramente no campo da Educação Física, quando a intenção é caracterizar uma prática esportiva realizada por atletas, no âmbito oficial das federações esportivas. Apesar dos limites dessa noção, ela ajuda a distinguir de outras formas de pensar e viver o esporte, como o esporte de lazer e o esporte educacional (sobre isso, ver STIGGER, 2005).
} 
desse jeito aqui, tinha que fechar a academia, ia ficar sem aluno. Aqui eu tive que montar um circuito, comprar luvas, comprar todo o equipamento, começar a falar dos benefícios do boxe, assim, não pra lutar, mas pra condicionamento físico também.

Nesse relato, Ricardo esclarece como adaptou alguns elementos e argumentos relacionados com a ginástica (treinos em circuito, discursos sobre benefícios físicos da atividade) para que o boxe pudesse ser inserido na academia. Dessa maneira, ele estava desenvolvendo uma forma de (re)apropriação do boxe, articulandoo com aspectos usualmente encontrados nas academias de fitness. Informações como essas também foram constantes nas falas dos alunos em suas entrevistas, onde os resultados referentes à luta e à aptidão física se relacionam. É o que o ex-praticante de boxe, Eduardo, expressa em depoimento sobre os seus objetivos em relação a esse esporte:

O que me chamou atenção no boxe foi o treinamento mesmo. Tanto que quando eu treinava boxe, eu perdi muitos quilos. E isso é uma coisa importante, eu achava uma atividade física muito boa e eu não sentia o sofrimento de fazer uma atividade física com obrigação de fazer uma atividade física pra emagrecer, o boxe era uma coisa que unia o útil ao agradável né, ele é uma coisa que me chamava a atenção, que eu gostei do treinamento, gostei do esporte em si e, claro, fazia um bem pra mim, eu emagrecia fácil com boxe e me sentia bem treinando boxe. [...] Acho que é importante também a técnica, e eu acho que seria mais difícil o cara me acertar um soco assim, acho que é positivo. Acho que foi importante até saber se defender.

Por um lado, esse depoimento indica como o condicionamento físico proporcionado pela modalidade foi decisivo para a sua escolha pelo boxe, enquanto atividade física a ser praticada. Porém, Eduardo também se refere a esse esporte como uma luta capaz de ajudá-lo em necessidade de autodefesa. Eduardo não menciona uma possível participação em competições esportivas, mas, sim, valoriza a incorporação das técnicas de luta numa dimensão utilitária, a da 
autodefesa. Estaria ele se referindo a uma prática do boxe que se afastaria do universo esportivo?

Dentre outras, a relação entre Diego e Vítor, Renata e Laura, Ricardo e Eduardo, tratadas acima, mediadas pela prática do boxe da academia, nos coloca frente a questões sobre os distintos interesses, objetivos e significados das práticas. Contudo, é preciso escapar dos binarismos. Uma possibilidade de pensar respostas é fugir destas oposições (tal como o apresentado no quadro 1, na introdução, que utilizamos para problematizar o tema) e considerarmos a noção de "hibridação" de Canclini (2008). Para o autor, este conceito é definido como "processos socioculturais nos quais estruturas ou práticas discretas, que existiam de forma separada, se combinam para gerar novas estruturas, objetos e práticas" (p. 19). Nesse sentido, as práticas do boxe de combate nos ringues e do fitness, combinadas, reconvertidas, geram, obliquamente, o que estamos denominando de boxe da academia, que possui características ou lógicas próprias, reinscrevendo as práticas em novas condições de produção e mercado (simbólico). Este processo de hibridização não significa uma substituição cultural, mas um desmoronamento de pares oposicionais (tradicional-moderno; hegemônico-subalterno) usados para falar do popular. A consideração de tal processo, agora, nos faz problematizar a própria noção de esporte.

\section{DESESPORTIVIZAÇÃO dO BOXE?}

Uma análise acerca dos debates sociológicos e históricos sobre esporte nos leva a identificar grupos de autores que percebem o desenvolvimento desse fenômeno a partir de diferentes pontos de vista. Alguns deles, como Guttmann (1978) e Mandell (1986) adotando uma lógica analítica de continuidade - diriam que os seres humanos sempre praticaram esportes, desde o chamado Esporte Primitivo até o Esporte Moderno, passando pelo Esporte Grego, pelo Esporte Romano e pelo Esporte Medieval. Outros estudiosos consideram que aquilo que hoje é praticado por todo o mundo sob a 
denominação de esporte, se originou na Inglaterra e dali se disseminou pelo mundo, principalmente no final do século XIX e início do século XX (ELIAS; DUNNING, 1992; HOBSBAWN; RANGER, 1984; BOURDIEU, 1986) ${ }^{14}$.

Dentre esses autores, Elias e Dunning (1992) relacionam o surgimento do esporte ao que denominam de processo de civilização iniciado na Inglaterra do século XVIII, quando identificava-se - na população inglesa - um aumento de sensibilidade em relação à violência. Juntamente com a parlamentarização do Estado Inglês, esse processo teria interferido na passagem dos jogos aos esportes, fundamentalmente no que se refere à coerção da violência e ao aumento da cadeia de interdependências. Assim sendo, alguns dos antigos passatempos (atribulados, desorganizados e violentos) se transformariam em esportes e se caracterizariam por "confrontos altamente regulamentados, exigindo esforço físico e competência técnica, caracterizados na sua forma de espetáculo como "desporto" (ELIAS; DUNNING, 1992, p. 46). Eles defendem então que, já no século XVIII, começava o que denominaram de um "processo de desportivização" (ELIAS; DUNNING, 1992, p. 224) dos passatempos populares. Mediante essa estruturação rígida e esportivizada, discorrem sobre o boxe:

O padrão popular de luta desarmada envolvendo os punhos, ainda que não estivesse totalmente desprovido de regras, era bastante flexível. A luta com os nós dos dedos desprotegidos, como muitos outros combates corporais, assumiu as características de um desporto na Inglaterra [...]. A introdução das luvas, o acolchoamento destas e a introdução de várias categorias de peso, garantiriam um nível superior de igualdade de oportunidades (ELIAS; DUNNING, 1992, p. 42).

Deste ponto de vista também destacam que os esportes se inserem nas atividades de lazer atuais, as quais são produtoras de tensões de um tipo particular (uma agradável tensão-excitação), que é fundamental para a satisfação no lazer e "essencial para a saúde

\footnotetext{
${ }^{14}$ Esse debate está mais detalhado em Stigger (2005).
} 
mental" (ELIAS; DUNNING, 1992, p. 137-138). Ao enfatizarem uma forma não negativa de pensar a tensão, a busca de uma tensãoexcitação também faria parte dos elementos constitutivos do esporte, onde a procura pela paridade entre os competidores seria um ponto importante na relação entre as práticas esportivas e os praticantes. Considerando que o jogo se concretiza nas relações de interdependência entre os seus participantes, defendem que o mesmo será prejudicado se estas relações forem demasiadamente rígidas, ou excessivamente flexíveis: "quando se assiste a um jogo de futebol, não é apenas o clímax representado pela vitória da nossa equipe que oferece emoção e prazer. Com efeito, se o jogo é, em si mesmo, desinteressante, até o triunfo da vitória pode ser, de certo modo, uma desilusão" (ELIAS; DUNNING, 1992, p. 47-48). É neste sentido que os autores consideram que seja adequado abandonar "o sentido negativo do conceito convencional de tensão e substituí-lo por outro que permita uma tensão ótima normal" (ELIAS; DUNNING, 1992, p. 137).

Esse olhar para os esportes ajuda a compreender o que se identifica nas posições de Renata que, em dois momentos, se refere à tensão-excitação que o esporte proporciona. Ao destacar que sua preferência é a atividade de sparring porque "é mais emocionante" e ao reclamar de Laura porque "ela não se esforça", se refere à tensãoexcitação ou às emoções agradáveis que, segundo Elias e Dunning, o esporte proporciona. Na visão da aluna, o jogo do boxe deve ser desenvolvido durante as aulas para que "tenha graça". Na mesma direção, Eduardo, ao estranhar o comportamento de Diego que não tem vontade de "fazer luvas", mas quer apenas realizar exercícios no saco de pancada, representa que o significado atribuído pelo primeiro vai ao encontro do discurso de Renata.

Porém, se por um lado Renata e Eduardo, assim como outros frequientadores citados, se preocupam em lutar boxe e atribuem à luta um caráter esportivizado, Laura e Diego, pouco preocupados com essas questões, conferem outras representações ao boxe. Mediado pelos elementos do fitness, o boxe da academia se torna uma prática individualizada para esses sujeitos, sem confronto, sem 
o jogo, o que se distancia das atribuições conferidas pelos autores citados anteriormente.

Além disso, a fala de Ricardo, quando se refere às diferenças encontradas por ele no boxe praticado nos Estados Unidos ${ }^{15}$ e o modo como ele inseriu a luta em sua academia ${ }^{16}$, acentua as diferenças entre a luta e a ginástica. A descrição feita em relação a como vivia o boxe no seu país de origem se relaciona com os resultados dos trabalhos sobre esportes de combate, e a definição da academia vai de encontro dos estudos sobre as academias de ginástica e musculação. A partir dessas relações - pela ausência de competições, de regras rígidas e, algumas vezes, sem o objetivo de lutar -, concluímos que, mediado pelo fitness, nesse local, o boxe é reapropriado e, de certa forma, desesportivizado. Isso no sentido de que, como uma prática em particular, autoreferenciada, o boxe admite outras práticas e referências de corpo, de técnicas e de significados.

Com base nessas referências, os resultados levaram a entender o boxe a partir de sua diversidade. Logo, ao encontrar um local em que essa luta é praticada com objetivos e sentidos que não se limitam ao do boxe que é hegemonicamente difundido, confirma-se o olhar sobre a heterogeneidade do boxe, este, definido a partir do contexto sociocultural e dos objetivos dos seus participantes, que misturam e reconvertem criativamente as práticas do boxe e do fitness. Além de localizar essa diversidade relacionada aos diferentes grupos de praticantes, encontrou-se uma heterogeneidade no interior do grupo, na medida em que, na mesma academia e na mesma aula, havia indivíduos que viam o boxe a partir dos seus fins estéticos, a sua noção fitness, e também frequientadores que identificavam o boxe na sua relação com a noção de luta; havia ainda praticantes que viviam o boxe mesclando essas duas noções. Quer dizer, a tomada do boxe da academia dentro de um "processo de hibridação" (CANCLINI, 2008), nos coloca frente a uma nova forma não estável, ao invés disso, repleta de heterogeneidades contínuas e dinamicamente elaboradas.

\footnotetext{
15"Lá, o objetivo é lutar".

${ }^{16 " A q u i, ~ t i v e ~ q u e ~ f a l a r ~ d o s ~ b e n e f i ́ c i o s ~ f i ́ s i c o s ~ d o ~ b o x e, ~ d o ~ c o n d i c i o n a m e n t o " . ~}$
} 


\section{Considerações FINAIS}

Esse estudo foi motivado a partir de pelo menos dois aspectos: a observação do dia-a-dia de uma academia de fitness, onde o boxe parecia ser praticado de forma diversa da sua versão hegemonicamente conhecida e reconhecida; e numa perspectiva crítica sobre a forma como os esportes hegemônicos se destacam nos debates acadêmicos, em detrimento das práticas cotidianas, realizadas por pessoas comuns, vinculadas a uma diversidade de significados.

Após a análise do material empírico produzido via estudo etnográfico, identificamos formas diferentes de pensar e viver o boxe, o que configurava, inclusive, uma heterogeneidade no interior da academia, onde numa mesma aula, alguns praticantes buscavam fins estéticos que o boxe proporcionava, assim como freqüentadores que queriam aprender a lutar, visando a defesa pessoal. Sendo que o boxe, na perspectiva de competição não foi encontrado naquele local, chegamos a perguntar: estaríamos diante de um boxe desportivizado?

Tentando encontrar respostas para essas questões, encontramos em Canclini (2008) elementos que ajudam a compreender como ocorrem fusões de elementos culturais tradicionais e modernos no que se refere há formação de uma nova prática ou estilo. A noção de hibridação nos apontou para combinações entre o boxe tradicional e a prática do fitness, que se caracterizam pela inserção de elementos das duas atividades nas aulas observadas - não seria estranho referirmos a simultaneidade da "desesportivização do boxe" e "esportivização do fitness"17. Deste modo, a preocupação com o ganho de massa muscular, condicionamento aeróbico, a diminuição do percentual de gordura (fins estéticos) e o investimento nos aspectos técnicos e a aquisição de habilidades de luta se mesclam. Porém, mais do que isso, ali existem especificidades - como a autodefesa, não encontrada na literatura, mas referida nas entrevistas - que resultam tanto dos objetivos de constituição da academia, provenientes

\footnotetext{
${ }^{17}$ Sobre "esportivização do fitness", talvez um exemplo seja o desenvolvimento da transformação da "ginástica aeróbica" na forma de competições individuais e coletivas.
} 
de interesses do seu proprietário, como das finalidades que provavelmente poderiam ser relacionadas às histórias de vida, aos contextos sociais e aos objetivos de seus frequientadores ${ }^{18}$.

Contudo, por mais que reconheçamos o processo de hibridação constitutivo do boxe de academia estudado, para além disso, não podemos deixar de destacar a constatação/interpretação de que este híbrido não é acabado (ainda que predominem ou se mantenham algumas regularidades), pois se constitui nas disputas simbólicas, por vezes tensas, que colocam em pauta a heterogeneidade dos significados e diversas estratégias de legitimação. Isso nos levou a relativizar o quadro que apresentamos no início desse trabalho, o qual - já ressaltamos - não se pautava pelo interesse de demarcar universos por diferenças estanques. Reafirmamos isso, pois, no nosso estudo, encontramos pessoas que praticavam o boxe na academia de fitness, sem a pretensão de lutar - isso nos levou a refletir sobre a possibilidade de estarmos diante de um boxe desportivizado. Se fôssemos a uma academia de boxe tradicional, será que não encontraríamos boxeadores que - além do interesse pelas competições esportivas - não encontram no boxe uma forma de serem admirados pela forma física (beleza corporal) que o boxe proporciona? É provável que sim...

\footnotetext{
${ }^{18}$ As contribuições de Lahire (2002) talvez venham a ajudar a encontrar respostas para questionamentos desse gênero.
} 
Between the boxing gym and gym's boxing: an ethnographic study

Abstract: This work brings elements for the discussion on the diversity of meanings of "sportive" practices by ordinary people in the everyday of the cities. It does that from an ethnographic study of the boxing practice in the context of a fitness center in the city of Porto Alegre, observing the way it articulates the meanings of "boxer's boxing" and students' fitness, and if it implicates on a logic of unesportiveness. After the analysis and interpretation of the empiric material produced, we can conclude that the practice studied has a hybrid aspect, in the sense that it is characterized by insertion (very dynamic, tense and disputed) of elements and meanings of "boxing gym" and "gym's boxing". In this sense, it would not be strange to refer to the simultaneity of the "unesportivization of boxing" and the "sportivization of fitness".

Key-words: Boxing; Gym; Ethnography; Diversity.

Entre el gimnasio de boxe y el boxe del gimnasio: un estudio etnográfico

Resumen: Este trabajo trae elementos para a discusión sobre la diversidad de los significados de las prácticas "deportivas" por personas comunes, en el cotidiano de las ciudades. Hacemos eso a partir de un estudio etnográfico de la práctica de boxe en el contexto de un gimnasio de fitness de la ciudad de Porto Alegre, en vista de como esta articula los sentidos del boxe de los boxeadores y del fitness de los alumnos, y si esto implica en una lógica de desesportivización. Después del análisis y la interpretación del material empírico producido, pudimos concluir que la práctica estudiada tiene un aspecto híbrido, en el sentido de que se caracteriza por la inserción (muy dinámica, tensa, disputada) de elementos y significados del "gimnasio de boxe" y del "boxe del gimnasio". En ese sentido, no seria extraño referirnos a la simultaneidad de la "desesportivização del boxe" y "esportivização delfitness".

Palabras-claves:Boxe; Gimnasio; Etnografía; Diversidad 


\section{REFERÊNCIAS}

BOURDIEU, P. Razões práticas: sobre a teoria da ação. Campinas: Papirus, 1986.

BURGESS, Robert G. A pesquisa de terreno: uma introdução. Oeiras: Celta Editora, 1997.

CANCLINI, N. G. Culturas híbridas: estratégias para entrar e sair da modernidade. 4. ed. São Paulo: Editora da Universidade de São Paulo, 2008.

DAMO, A. S. Monopólio estético e diversidade configuracional no futebol brasileiro. Movimento, Porto Alegre, v. 9, n. 2, p. 129-156, maio/ago. 2003.

ELIAS, N.; DUNNING, E. A busca da excitação. Lisboa: Difel, 1992.

FARIA, C.P. Corpos no Ringue: encontros de discursos e práticas, representações e imagens na experiência da participação em um "projeto social" entre jovens moradores da Maré (RJ). 175 f. Dissertação (Mestrado) - Programa de PósGraduação em Sociologia e Antropologia, Universidade Federal do Rio de Janeiro, Rio de Janeiro, 2005.

GUTTMANN, A. From ritual to Record: the nature of modern sports. New York: Columbia University, 1978.

HOBSBAWN, E.; RANGER, T. (Org.). A invenção das tradições. Rio de Janeiro: Paz e Terra, 1984

LAHIRE, B. Homem plural: os determinantes da ação. Petrópolis: Vozes, 2002.

MAGNANI, J. G. C. Discurso e representação ou de como os Baloma de Kiriwana podem reencarnar-se nas atuais pesquisas. In: CARDOSO, R. (Org.). A aventura antropológica: teoria e pesquisa. 3. ed. Rio de Janeiro: Paz e Terra, 1997.

O MAIOR de todos: a história de uma lenda que varreu todo o mundo. Documentário. Produção de John Marshall, Ernest Borgnine, John Marley e Lloyd Haynes. Direção de Tom Gries. Manaus: Videolar, sob licença de Columbia TriStar Home Entertainment do Brasil, 2001. 1 DVD (101 min.): Digital, Color., Inglês, Legendado. Português.

MALYSSE, S. Em busca dos (H) alteres-ego: olhares franceses nos bastidores da cultura carioca. In: GOLDEMBERG, M. (Org.). Nu e vestido: dez antropólogos revelam a cultura do corpo carioca. Rio de Janeiro: Record, 2002.

MANDELL, R. História cultural del esporte. Barcelona: Edicions Bel-laterra, 1986

MARQUES, R. F. R.; ALMEIDA, M. A. B. de; GUTIERREZ, G. L. Esporte: um fenômeno heterogêneo: estudo sobre o esporte e suas manifestações na sociedade contemporânea. Movimento. Porto Alegre, v. 13, n. 3, p. 225-242, set./dez., 2007. 
MUHAMMAD ALI. Aos olhos do mundo. Documentário. Produção de Phil Grabsky e Louise Murray. Documentário. Direção de Phil Grabsky. Manaus: Microservice Tecnologia Digital da Amazônia, sob licença da Universal Pictures Internacional BV, 2001. 1 DVD (109 min.): Digital, Color., Legendado. Português.

OLIVEIRA, R. C. O trabalho do antropólogo: olhar, ouvir e escrever. Revista de Antropologia, São Paulo, v. 39, n. 1, p. 17-36, 1996.

PADIGLIONE, V. Diversidad y pluralidade en el escenario deportivo. Apunts: Educación Física y Deportes, Barcelona, n. 41, p. 30-35, 1995.

SAUTCHUK, C.E. A medida da gordura: o interno e o íntimo na academia de ginástica. Mana, Rio de Janeiro, v. 13, n. 1, p. 181-205, 2007.

STIGGER, M. P. Futebol de veteranos: um estudo etnográfico sobre o esporte no cotidiano urbano. Movimento, Porto Alegre, v. 4, n. 7, p. 52-66, 1997.

Esporte, lazer e estilos de vida: um estudo etnográfico. Campinas: Autores Associados, 2002.

O esporte na cidade: estudos etnográficos sobre sociabilidade esportiva em espaços urbanos. 2. ed. Porto Alegre: Editora da UFRGS, 2007.

WACQUANT, L. Os três corpos do lutador. In: LINS, D. A. (Org.). Dominação masculina revisitada. Campinas: Papirus, 1998.

Whores, slaves and stallions: languages of exploitation and accommodation among boxers. Body and Society, v. 7, n. 2-3, p. 181-194, 2001.

Corpo e alma: notas etnográficas de um aprendiz de boxe. Rio de Janeiro: Relume Dumará, 2002.

2003.

A zona. In: BOURDIEU, P. (Org.). A miséria do mundo Petrópolis, Vozes:

Un traficante de carne en acción: pasión, poder y lucro en la economía del boxeo profesional. In: LACHAUD, J. M.; NEVEUX, O. (Org.). Cuerpos dominados, cuerpos en ruptura. Buenos Aires: Nueva Visión, 2007.

WINKIN, Y. Descer ao campo. In: A nova comunicação: da teoria ao trabalho de campo. Campinas: Papirus, 1998 . p. 129-145.

Endereço para correspondência:

Praça Dom Feliciano 56/ ap 11. Centro histórico.

Porto Alegre-RS

CEP: $90020-160$.

Recebido em: 22/09/2011

Aprovado em: 19/01/2012 
